\title{
Acknowledgments
}

There were many people who helped to make this book possible. My thanks first goes to Chung Mingli, Shek Pingkwan, May Wong, Li Hangtung, Nana Lau, Chen Juying, Wang Keqin, She Yinhu, and Li Bianfeng. Without them my fieldwork in Guangdong, Hunan, Sichuan, Chongqing, Beijing, and Hong Kong would not have been possible. I would also like to express my gratitude to Professor Pun Ngai, Apo Leung, Choi Yukyuk, Monina Wong, Francine Chan, Alan Sze, Huang Leping, Ye Mingxin, Wang Shengli, and Li Guoguang for their invaluable information and insights.

Throughout this project, many have offered critical comments which have helped form this book. For such help, I wish to thank Chan Kingchi, Cheung Chaukiu, Wu Keungfai, Fung Saifu, Chen Fenling, and Professor Chui Winghong. My sincere thanks go to Ho Kitho for his outstanding research assistance, and Jennifer Eagleton for her excellent proof-editing work which has turned my prose into a more readable text.

I have dedicated this book to my wife Christine, and my children Ronald and Nicole who have tolerated my absence at home during fieldwork and the final stage of writing up the manuscript.

I feel deep regret that in order to protect the anonymity of the sick workers I talked to and lived with, and that of my fieldwork assistants who also became sick, I cannot mention them by name. I am particularly grateful for their hospitality in welcoming me into their homes in villages in Hunan, Sichuan, and Chongqing. Being sufferers of an incurable disease and victims of the current system, they have helped me not only to understand their own experiences but they have also enabled me to connect with others in similar situations.

Last but not least, I am grateful to the New Ethnographies series editor Alex Smith for his unswerving confidence in this book project, to Manchester University Press for its efficient review process, and two anonymous reviewers for their constructive, and sometimes sympathetic, comments on the manuscript.

Although I would not have arrived at my final draft without the help of those already mentioned, I bear sole responsibility for any errors, omissions, and inaccuracies in the text. 
Data from the early stage of my fieldwork have appeared in The China Quarterly, China Review: An Interdisciplinary Journal on Greater China, and China: An International Journal. I would like to take this opportunity to extend my gratitude to the editors and blind reviewers of these journals whose inputs and comments have greatly improved the book.

At different stages, my study was supported by three grants. They are Marginality, Suffering, and (Dis-)empowerment: A Study of the "Multiple Exits" for Victims of Work-induced Pneumoconiosis in China (granted by the College of Liberal Studies and Social Sciences, City University of Hong Kong; ref\# 9610250); Occupational Poisoning and Body Politics in Post-Deng China: Female Peasantworkers' Testimonies both at and away from Home (granted by the College of Liberal Studies and Social Sciences, City University of Hong Kong; ref\# 9610202); and Exploring "Localism" vis-à-vis Central Strategy: A Study of Cultural Schema Pertinent to the 2010 "Save-Cantonese" Protests (granted by the UGC-General Research Fund (GRF); ref\# 144012).

\section{A note on anonymity}

When I began fieldwork, I promised anonymity to the people whom I interviewed. Therefore, all personal names in this book, save those of widely recognized public figures, are pseudonyms. However, special consent has been given for photographs in which individuals can be identified.

\section{A note on verbatim quotation}

In this book, "..." connotes a natural pause in the utterance of the actor; "[...]" means that one or several sentences are skipped to avoid the verbatim quotes from being too long and superfluous. 